\title{
KNOWLEDGE OF DIABETES AMONG TYPE 2 DIABETES PATIENTS AND THEIR BLOOD GLUCOSE LEVEL- A CROSS-SECTIONAL STUDY
}

\author{
Shyamal Roy1, Taranga Reang ${ }^{2}$
}

${ }_{1}^{1}$ Associate Professor, Department of Medicine, Agartala Govt. Medical College and GB Pant Hospital, Agartala, Tripura.

${ }^{2}$ Assistant Professor, Department of Community Medicine, Agartala Govt. Medical College and GB Pant Hospital, Agartala, Tripura.

\begin{tabular}{l}
\hline ABSTRACT \\
BACKGROUND \\
Prevalence of type 2 diabetes mellitus is rising worldwide and increasingly being recognised in relatively young people due to the \\
high prevalence of environmental and genetic risk factors. The objectives of this study is to assess knowledge, lifestyle habits and \\
blood glucose level of diabetes patients.
\end{tabular}

\section{MATERIALS AND METHODS}

A cross-sectional study was conducted among 100 diabetics and systematic random sampling was used for selection of study subject. We used oral questionnaire for assessing knowledge, lifestyle habits, and height and weight measured to calculate BMI. The means, standard deviations and frequencies were calculated. For inferential statistics, Chi-square $\left(\mathrm{X}^{2}\right)$ test was used to determine the strength of association between dependent and independent variables. $\mathrm{P}$ values $<0.05$ were considered as statistically significant.

\section{RESULTS}

Eighty five percent (85\%) of the respondents knew that diabetes is due to high blood sugar, familial (43\%), sedentary workers can suffer (44\%) and it affects kidney, heart, liver and eyes (49\%). Fifty two percent among participants did physical activities for one to two hours per day, $17 \%$ smoked and majority were rice eaters. It was found that $57 \%$ of the respondents' HbA1C levels were less than $7.0 \%$ suggesting control of diabetes. The high cholesterol level is associated with high HbA1C values ( $p=0.002)$.

\section{CONCLUSION}

The control of blood sugar among diabetes patients was fifty seven percent in spite of having good knowledge. More than half of participants having some type of physical activities, which may need to improve in terms of hours per day or hours per week. The literacy and lifestyle habits did not show any significant association with diabetes control among the study population.

\section{KEYWORDS}

Diabetes Mellitus Type 2, Knowledge, Lifestyle Habits, Blood Sugar Level and Diabetes Control.

HOW TO CITE THIS ARTICLE: Roy S, Reang T. Knowledge of diabetes among type 2 diabetes patients and their blood glucose level- a cross-sectional study. J. Evolution Med. Dent. Sci. 2018;7(05):597-602, DOI: 10.14260/jemds/2018/136

\section{BACKGROUND}

The Diabetes mellitus type $2\left(\mathrm{DM}_{2}\right)$ is more in the developing countries, which unfortunately are already suffering from communicable diseases.(1) The incidence of diabetes mellitus (DM) have continued to increase globally with the resulting burden resting more heavily on tropical, developing countries.(2,3) Type 2 DM, which is the more common, is increasingly being recognised in relatively young persons due to the high prevalence of environmental and genetic risk factors.(3) People living with type $2 \mathrm{DM}$ are more vulnerable to varied forms of both short- and long-term complications, which often lead to their premature death. It is predicted that prevalence of $\mathrm{DM}_{2}$ in adults will increase in the next two decades and much of the increase will occur in developing countries where the majority of patients are aged between 45 and 64.(4-5)

'Financial or Other Competing Interest': None.

Submission 22-12-2017, Peer Review 14-01-2018,

Acceptance 22-01-2018, Published 29-01-2018.

Corresponding Author:

Dr. Taranga Reang,

Assistant Professor

Department of Community Medicine,

Agartala Govt. Medical College and GB Pant Hospital,

Agartala- 799006, Tripura.

E-mail: tarangareang@gmail.com

DOI: $10.14260 /$ jemds $/ 2018 / 136$
It is estimated that over $70 \%$ of people with diabetes will reside in developing countries by the year 2030.(6,7) In 2011, the Diabetes Atlas of the International Diabetes Federation (IDF) estimated the global $\mathrm{DM}_{2}$ prevalence in the age group of 20 - 79 years at $8.3 \%$, which translates into 366.2 million people suffering from $\mathrm{DM}_{2}$ in 2011. The number of people living with $\mathrm{DM}_{2}$ is projected to reach 551.9 million by 2030 (Whiting et al, 2011).(8) Although, hyperglycaemia often presents with few outward symptoms, tight control of blood glucose is needed to prevent many of the short- and longterm complications of type 2 diabetes. A blood glucose control goal requires active patient participation in order to master a complex array of self-management skills. These include modifying dietary choices, implementing exercise regimes, monitoring blood glucose and adhering to often complex medication regimens.(9-10) Suboptimal treatment can lead to increased use of health care services, reduction in patient's quality of life and increased health care costs. $(11,12,13)$ Inadequate to anti-diabetes medication can cause treatment failure leading to diabetes-related complications, such as retinopathy, neuropathy, nephropathy, etc., reduced quality of life. Proper management requires lifestyle changes and adequate diabetes knowledge of which is considered a key component of diabetes management. Differences in knowledge level have been described depending on level of education, gender and social classes.(14) 
Those diabetic patients who are having low literacy and low knowledge might be facing troubles in learning self-care skill for glycaemic control.(15) This could be caused by illiteracy, cognition influence, decreasing vision and hearing status as a result of aging process.(16) Among patients with low literacy, intervention patients were more likely than control patients to achieve goal HbA1C levels. Patients with higher literacy had similar odds of achieving goal HbA1C levels regardless of intervention status. (17)

Our intention of this study is to assess knowledge among type 2 diabetes patients and their blood glucose level at tertiary care hospital in Agartala city located in the North Eastern part of India. It can help create awareness among diabetes patients and prevent disability. It may be helpful to administrators for better planning and implementation in future.

\section{MATERIALS AND METHODS}

A cross-sectional study was conducted among 100 Diabetic patients attending Outpatient Department (OPD) of a tertiary care hospital of Agartala city, located in the North-Eastern part of India. The sample size was calculated using formula for single proportion $Z 1-\alpha / 2^{2} p(1-p) / L^{2}$. The ' $p$ ' is assumed 0.5 with $95 \%$ confidence interval and $5 \%$ level of significance. The margin of error was taken as $20 \%$ in the present study. The systematic random sampling technique was used for selection of the study subjects. Simple random sampling (lottery method) was used for the first patients to get the starting point. Thereafter, depending on sampling interval patients coming to the clinic were enrolled in the study until the required sample size was achieved. Patients aged $\geq 20$ years diagnosed with $\mathrm{DM}_{2}$ for duration of six months or more were included in the study. Seriously ill patients and requiring dialysis were excluded from the study. Diabetes was defined as fasting plasma glucose $\geq 126 \mathrm{mg} / \mathrm{dL}$ and postprandial plasma glucose $>200 \mathrm{mg} / \mathrm{dL}$. Data were collected from individuals attending OPD using structured interview schedule. The questionnaire for the interview has had four sections: socio-demographic, knowledge, lifestyle habits, anthropometry and laboratory assessment. We also calculated BMI for the selected individuals. The independent variables to explain the knowledge etc. included patient related factors and social factors etc. The questionnaire was prepared in English and translated into local language while doing the interview. Each item had definitive 'yes/no' and other related response key. A scoring system was developed, whereby the total number of correct responses for the knowledge section was calculated for each respondent and percentage was created. Each correct answer was given one mark and the total mark calculated out of 100 . Knowledge was graded as very good (score $>80 \%)$, good $(60 \%-80 \%)$, average $(40 \%-60 \%)$ and poor $(<40 \%)$. Each questionnaire took approximately 15 minutes to administer. Data were obtained regarding glycaemic control as part of the routine screening. We considered the HbA1C cut-off value of $7.0 \%$ or above for poor control of diabetes.(18) The participants were requested to participate in the study voluntarily. Informed written consent was obtained from the participants before conducting the study. The information so collected was kept confidential and anonymous. The approval from Institutional Ethics Committee was obtained before conducting the study. The data were collected from June to September 30, 2017.

\section{DataAnalysis}

Data were checked, sorted, categorised and coded. After coding the data were entered to the computer to make it ready for processing and analysis. It was analysed by using the Microsoft Excel 2007 software. For Chi-square test, we used Epi-Info version 6.0. Descriptive statistics such as means, standard deviations and frequencies were calculated. For inferential statistics like Chi-square $\left(\mathrm{X}^{2}\right)$ test, ' $\mathrm{t}$ ' test were used to determine the strength of association between dependent and independent variables. $\mathrm{P}$ values $<0.05$ were considered as statistically significant.

\section{RESULTS}

Majority (36\%) of the respondents were from 40 - 50 years' age group, who were attending the diabetic clinic of the hospital. The overall mean (SD) age of the study subjects was 52.89 ( \pm 12.031 ) years. The mean (SD) age for male and female were 55.13 ( \pm 11.650$)$ years and 50.46 (12.083) years respectively. The proportion of male and female were almost similar (Male 52\%, Female 48\%). More than fifty percent $(51.0 \%)$ studied up to higher secondary level, $42 \%$ housewives and $65 \%$ of respondents' income was Rs. $<10,000$ only (Table 1). Sixty two percent $(62 \%)$ were from urban community and $76 \%$ belonged to joint family. Sixty nine percent were from general category, 3\% indigenous (Schedule Tribe) and remaining 28\% from schedule caste (SC) category. Seventeen percent (17\%) of the respondents were smokers, $36 \%$ used alcohol occasionally and $64 \%$ rice eaters (Table 2). Eighty five percent (85\%) of the respondents knew that diabetes is due to high blood sugar, familial (43\%), sedentary workers can suffer (44\%), affecting kidney, heart, liver and eyes (49\%), whereas $61 \%$ said preventable. The knowledge scores in very good, good and average categories were $74 \%, 24 \%$ and $2 \%$ respectively. It was found that $57 \%$ of the respondents' HbA1C level were less than $7.0 \%$ suggesting control over diabetes. We further found that only $24 \%$ and $76 \%$ respondents' fasting and $2 \mathrm{hrs}$. post glucose level were $<125 \mathrm{mg} \%$ and $\leq 200 \mathrm{mg} \%$ respectively. The lipid profile of $76 \%, 83 \%, 66 \%$ and $81 \%$ respondents' total cholesterol, HDL, LDL and VLDL levels in terms of $\mathrm{gm} / \mathrm{dL}$ were $\leq 200, \geq 35$, within $70-130,>35$ respectively (Table 3 ). Among those who were having sugar control (HbA1C < 7.0\%), 75.0\% of them do physical activity for 60 - 120 minutes per day. The literacy, gender, physical activity and its duration, knowledge on diabetes, duration of treatment and BMI did not show any significant association with blood sugar control. But interestingly the higher cholesterol level is associated with uncontrolled blood sugar level ( $\mathrm{p}=0.002)$ (Table 4).

\begin{tabular}{|c|c|c|}
\hline Variables & Number (N) & Percentage (\%) \\
\hline \multicolumn{3}{|c|}{ Age Group (yrs.) } \\
\hline $20-30$ & 3 & 3.0 \\
\hline $30-40$ & 8 & 8.0 \\
\hline $40-50$ & 36 & 36.0 \\
\hline $50-60$ & 31 & 31.0 \\
\hline$>60$ & 22 & 22.0 \\
\hline \multicolumn{3}{|c|}{ Sex } \\
\hline Male & 52 & 52.0 \\
\hline Female & 48 & 48.0 \\
\hline \multicolumn{3}{|c|}{ Income (Rs.) } \\
\hline$<10,000$ & 65 & 65.0 \\
\hline $10,000-20,000$ & 26 & 26.0 \\
\hline$>20,000$ & 9 & 9.0 \\
\hline
\end{tabular}




\begin{tabular}{|c|c|c|}
\hline \multicolumn{3}{|c|}{ Occupation } \\
\hline Govt. employee & 24 & 24.0 \\
\hline Businessman & 11 & 11.0 \\
\hline Daily labourer & 23 & 23.0 \\
\hline House wife & 42 & 42.0 \\
\hline \multicolumn{2}{|c|}{ Literacy Status } \\
\hline Illiterate & 5 & 5.0 \\
\hline Under matric & 38 & 38.0 \\
\hline Higher secondary & 51 & 51.0 \\
\hline $\begin{array}{c}\text { Graduate and } \\
\text { above }\end{array}$ & 6 & 6.0 \\
\hline \multicolumn{2}{|c|}{ Duration of Diabetes } \\
\hline 1-5 years & 46 & 46.0 \\
\hline 5-10 years & 35 & 35.0 \\
\hline 10-15 years & 15 & 15.0 \\
\hline >15 years & 4 & 4.0 \\
\hline Table 1. Socio-Demographic Profile of the Participants \\
\hline \multicolumn{2}{|c|}{} \\
\hline
\end{tabular}

\begin{tabular}{|c|c|c|}
\hline Smoking Habits & Number (N) & Percentages (\%) \\
\hline Smoker & 17 & 17.0 \\
\hline Non-smoker & 37 & 37.0 \\
\hline Quitter & 5 & 5.0 \\
\hline Irregular & 10 & 10.0 \\
\hline Non-smokers & 31 & 31.0 \\
\hline \multicolumn{3}{|c|}{ Alcohol } \\
\hline Irregular use & 2 & 2.0 \\
\hline 2 packs per day & 2 & 2.0 \\
\hline$>2$ packs per day & 1 & 1.0 \\
\hline Occasionally & 36 & 36.0 \\
\hline Non-drinkers & 58 & 58.0 \\
\hline \multicolumn{3}{|c|}{$\begin{array}{l}\text { Major Staple Food Consumption } \\
\end{array}$} \\
\hline Rice & 64 & 64.0 \\
\hline Roti & 3 & 3.0 \\
\hline Rice and roti & 25 & 25.0 \\
\hline $\begin{array}{l}\text { Roti at night and } \\
\text { rice in lunch }\end{array}$ & 8 & 8.0 \\
\hline \multicolumn{3}{|c|}{ Physical Activity Time (min) } \\
\hline$<30$ mins & 1 & 1.0 \\
\hline $30-60$ mins & 8 & 8.0 \\
\hline $60-120$ mins & 52 & 52.0 \\
\hline$>120$ mins & 9 & 9.0 \\
\hline No physical activity & 30 & 30.0 \\
\hline
\end{tabular}

\begin{tabular}{|c|c|c|}
\hline HbA1C Level (\%) & Number (N) & Percent (\%) \\
\hline$<7.0$ & 57 & 57.0 \\
\hline$\geq 7.0$ & 43 & 43.0 \\
\hline \multicolumn{3}{|c|}{ Blood Sugar Level (mg/dL) } \\
\hline \multicolumn{3}{|c|}{ Fasting (mg/dL) } \\
\hline$\leq 125$ & 24 & 24.0 \\
\hline$\geq 126$ & 76 & 76.0 \\
\hline \multicolumn{3}{|c|}{ 2 hrs. Post Glucose Test (mg/dL) } \\
\hline$\leq 200$ & 76 & 76.0 \\
\hline$>200$ & 24 & 24.0 \\
\hline \multicolumn{3}{|c|}{ Serum Cholesterol (mg/dL) } \\
\hline$\leq 200$ & 76 & 76.0 \\
\hline$>200$ & 24 & 24.0 \\
\hline \multicolumn{3}{|c|}{ HDL Cholesterol (mg/dL) } \\
\hline$<35$ & 17 & 17.0 \\
\hline$\geq 35$ & 83 & 83.0 \\
\hline \multicolumn{3}{|c|}{ LDL Cholesterol (mg/dL) } \\
\hline $70-130$ & 31 & 31.0 \\
\hline$>130$ & 66 & 3.0 \\
\hline
\end{tabular}

\begin{tabular}{|c|c|c|}
\hline \multicolumn{3}{|c|}{ VLDL Cholesterol (mg/dL) } \\
\hline $12-35$ & 19 & 19.0 \\
\hline$>35$ & 81 & 81.0 \\
\hline \multicolumn{2}{|c|}{ Table 3. Laboratory Profile of DM2 Patients } \\
\hline
\end{tabular}

\begin{tabular}{|c|c|c|c|}
\hline \multirow{2}{*}{ Variables } & \multicolumn{2}{|c|}{ HbA1C, N (\%) } & \multirow{2}{*}{ P value } \\
\hline & $<7.0 \%$ & $\geq 7.0 \%$ & \\
\hline \multicolumn{4}{|c|}{ Literacy } \\
\hline Illiterate & $2(3.5)$ & $3(7.0)$ & \multirow{4}{*}{0.304} \\
\hline Under matric & $24(42.1)$ & $14(32.6)$ & \\
\hline $\begin{array}{c}\text { Higher } \\
\text { secondary }\end{array}$ & $26(45.6)$ & $25(58.1)$ & \\
\hline $\begin{array}{c}\text { Graduate and } \\
\text { above }\end{array}$ & $5(8.8)$ & $1(2.3)$ & \\
\hline \multicolumn{4}{|c|}{ Physical Activity } \\
\hline Yes & $48(84.2)$ & $36(83.7)$ & \multirow{2}{*}{0.947} \\
\hline No & $9(15.8)$ & $7(16.3)$ & \\
\hline \multicolumn{4}{|c|}{ Physical Activity Time (min) } \\
\hline$<30$ mins & $1(2.6)$ & $0(0.0)$ & \multirow{4}{*}{0.695} \\
\hline $30-60$ mins & $4(10.3)$ & $4(12.9)$ & \\
\hline $60-120$ mins & $30(76.9)$ & $22(71)$. & \\
\hline$>120$ mins & $4(10.3)$ & $5(16.1)$ & \\
\hline \multicolumn{4}{|c|}{ Knowledge Score of Participants } \\
\hline $\begin{array}{c}\text { Very Good } \\
(>80 \%)\end{array}$ & $40(70.2)$ & $34(79.1)$ & \multirow{3}{*}{0.091} \\
\hline $\begin{array}{c}\text { Good (60\%- } \\
80 \%)\end{array}$ & $17(29.8)$ & $7(16.3)$ & \\
\hline $\begin{array}{c}\text { Average (40\%- } \\
60 \%) \\
\end{array}$ & $0(0.0)$ & $2(4.7)$ & \\
\hline \multicolumn{4}{|c|}{ Treatment Duration } \\
\hline$\leq 5$ yrs. & $29(50.9)$ & $25(58.1)$ & \multirow{3}{*}{0.270} \\
\hline 6-10 yrs. & $20(35.1)$ & $9(20.9)$ & \\
\hline$>10$ yrs. & $8(14.0)$ & $9(20.9)$ & \\
\hline \multicolumn{4}{|c|}{ Serum Cholesterol (gm/dL) } \\
\hline $120-200$ & $50(87.7)$ & $26(60.5)$ & \multirow{2}{*}{0.002} \\
\hline$>200$ & $7(12.3)$ & $17(39.5)$ & \\
\hline \multicolumn{4}{|c|}{ Sex } \\
\hline Male & $28(49.1)$ & $24(55.8)$ & \multirow{2}{*}{0.323} \\
\hline Female & $29(50.9)$ & $19(44.2)$ & \\
\hline \multicolumn{4}{|c|}{ BMI } \\
\hline$<18.5$ & $0(0.0)$ & $2(4.7)$ & \multirow{3}{*}{0.255} \\
\hline $18.5-24.99$ & $38(66.7)$ & $28(65.1)$ & \\
\hline$\geq 25$ & $19(33.3)$ & $13(30.2)$ & \\
\hline \multicolumn{4}{|c|}{$\begin{array}{l}\text { Table 4. The Association of Physical Activity, Duration of } \\
\text { Physical Activity, Treatment Duration and Knowledge } \\
\text { with HbA1C Level }\end{array}$} \\
\hline
\end{tabular}

\section{DISCUSSION}

This study was conducted in a tertiary care hospital of Agartala city among 100 diabetics during June to September 2017 to assess knowledge of diabetes, lifestyle habits among $\mathrm{DM}_{2}$ patients and their blood sugar level. Knowledge on diabetes is crucial in controlling diabetes which includes healthy practices like exercise or regular physical activities, healthy food eating, avoidance of junk foods and self-care practices. The diabetes related knowledge can improve outcome of treatment and further help in preventing complications. In present study, 40 - 50 years' age group were representing more than other age group and male and female proportions were almost equal. The overall mean (SD) age was $52.89( \pm 12.031)$ years. A study from Western Nepal showed that the greatest number of patients was in the age group of 51 - 60 years and number of males was higher than females.(19) It could be due to proportion of $\mathrm{DM}_{2}$ patients were predominantly seen in these middle age groups. 
Ninety five percent of the respondents were literate and forty two percent housewives. In the present study, most of the respondents were from General Category (69\%) and only $3 \%$ from ST or indigenous population. A study from Nepal also reported that the participants' mean age $( \pm$ SD) was 52 (11.19) years and $66.7 \%$ were males, $48.5 \%$ belonged to indigenous caste. In regard to education level, $30.3 \%$ of the participants had higher secondary or above education and $21.2 \%$ were illiterates. About one-fourth of the participants were housewives, $15.2 \%$ government employees and $12.1 \%$ were farmers. Participants with history of diabetes for 1-5 years were $48.5 \%$, for more than 5 years were $30.3 \%$ and for less than 1 year were $21.2 \%$.(20) The present study showed that eighty five percent knew that diabetes is due to high blood sugar, which can be considered having good awareness on diabetes. The knowledge level was quite high, which might be due to information gathered from different sources. The participants were mainly from urban areas, accessible to local dailies and also in frequent touch with health personals. A study from Los Angeles county hospital showed poor knowledge of diabetes.(21) A study from Nepal also showed that diabetes knowledge was poor.(20) These contradictory results might be due to difference in assessment technique or difference in study tools used between the studies as they have used the DKQ-24 method, whereas we used simple questionnaire. But few studies from Nepal, South India, Karachi, United Arab Emirates and Kuwait showed almost similar pattern of result.(19,22-25) Studies from Andhra Pradesh, Sri Lanka and Malaysia showed satisfactory diabetes knowledge in diabetes patients.(26-28) Possibly, the comparability of our findings with that of South India might be due to similarity in the socio-demographic, dietary habits and behavioural characteristic of the participants. Further, comparability of health care services in both the regions might also impart almost similar level of knowledge to the diabetic patients. We could not find any significant association of knowledge with gender. Similar studies were reported from Nepal.(20) Studies from Kuwait and Bangladesh also reported almost similar pattern of findings.(29,30) Few studies showed higher diabetes knowledge among males. $(30,31)$ We did not find any significant association between duration of diabetes and knowledge. A study from Nepal reported that no significant association of diabetes duration and knowledge.(20) Jasper US et al also reported almost similar result.(32) However, some studies reported higher level of diabetes knowledge with duration of disease. $(21,25,33)$

In this study, rice is the major meal (97\%) consumed and $17.0 \%$ smokers and $36 \%$ drink alcohol occasionally. A study from Ethiopia reported that 10\% - 20\% carbohydrate, $40 \%$ $60 \%$ proteins, $20 \%-30 \%$ fat, small amount vitamins and minerals are advisable food for diabetic patients.(33) It is worthy to mention that rice is the major staple food consumed in this part of the country. A study from Pakistan showed that prevalence of cigarette smoking among type 2 diabetes mellitus patients was $27 \%$. There was significant association of male sex, number of cigarettes smoked in a day, duration of disease and duration of cigarette smoking.(34) In the present study, $57.0 \%$ were having HbA1C level $<7.0 \%$ and high VLDL among the study participants. The physical activity and its duration, knowledge on diabetes, duration of treatment and BMI did not show any significant association with blood sugar control. But interestingly, the cholesterol level positively correlated to $\mathrm{HbA1C}$ level $(\mathrm{p}=0.002)$. Exercise is shown to have significant impact on $\mathrm{HbA1C}$ in $\mathrm{DM}_{2}$ patients of group, i.e. walking and yoga respectively.(35) A study from Pakistan showed that HbA1C had non-significant and weak negative association with diabetes-related knowledge.(36) A study from Malaysia reported that $68 \%$ patients had $\mathrm{HbA} 1 \mathrm{c}$ $>6.5 \%$ and mean $\mathrm{HbA} 1 \mathrm{C}$ was $7.8 \%$. Younger patients had poorer glycaemic control than older patients, and most patients with poor glycaemic control were obese. It was revealed that age ( $<60$ years), sex (male), duration of diabetes ( $>5$ years), body mass index (obese), type of treatment (diet therapy vs. combination therapy) and abnormal lipid profile were significantly associated with increased odds of $\mathrm{HbA1C}>6.5 \%$.(37) A study from Nigeria showed that RBS increased significantly with increasing BMI status.(38)

\section{CONCLUSION}

The control of blood sugar among diabetes patients was fifty seven percent only, in spite of having good knowledge. More than half of participants having some type of physical activities, which may need to improve in terms of hours per day or hours per week. The literacy status and lifestyle habits did not show any significant association with diabetes control among the study population.

\section{Strength and Limitation}

We carried out this in hospital setting, accessible mainly by urban population. The blood values were based on their recent laboratory records. We cannot generalise the present study due to small sample size and limited to one hospital only.

\section{Recommendation}

We recommend further study involving more subjects including rural and urban population. Health awareness activities may be carried out more vigorously throughout the state to cover all population groups.

\section{ACKNOWLEDGEMENT}

We are thankful to all participants without whom this would not have been possible.

\section{REFERENCES}

[1] Ogbera AO, Kuku SF. Insulin use, prescription patterns, regimens and costs - a narrative from a developing country. Diabetology \& Metabolic Syndrome 2012;4(1):50.

[2] Wild S, Roglic G, Green A, et al. Global prevalence of diabetes: estimates for the year 2000 and projections for 2030. Diabetes Care 2004;27(5):1047-53.

[3] Lindgren CM, Hirschhorn JN. The genetics of type II diabetes. Endocrinologist 2001;11:178-87.

[4] Murray CJL, Lopez AD. Alternative projections of mortality and disability by cause 1990-2020: Global Burden of Disease Study Lancet 1997;349(9064):1498-504.

[5] Shaw JE, Sicree RA, Zimmet PZ. Global estimates of the prevalence of diabetes for 2010 and 2030. Diabetes Res Clin Pract 2010;87(1):4-14. 
[6] Inzucchi SE. Diabetes Facts and Guidelines. Takeda Pharmaceuticals, Yale Diabetes Center, Yale University, North America, Inc. 2011. https://www.yumpu.com/en/document/view/58090 26/diabetes-facts-and-guidelines-endocrinology-yaleuniversity. Accessed on 24/5/2017.

[7] Shaw JE, Sicree RA, Zimmet PZ. Global estimates of the prevalence of diabetes for 2010 and 2030. Diabetes Res Clin Pract 2010;87(1):4-14.

[8] Whiting DR, Guariguata L, Weil C, et al. IDF diabetes atlas: global estimates of the prevalence of diabetes for 2011 and 2030. Diabetes Res Clin Pract 2011;94(3):311-21.

[9] Rozenfeld Y, Hunt JS, Plauschinat C, et al. Oral antidiabetic medication adherence and glycemic control in managed care. Am J Manag Care 2008;14(2):71-5.

[10] Ho PM, Rumsfeld JS, Masoudi FA, et al. Effect of medication non-adherence on hospitalization and mortality among patients with diabetes mellitus. Arch Intern Med 2006;166(17):1836-41.

[11] World Health Organization. Adherence to long-term therapies: evidence for action. World Health Organization, Geneva, Switzerland 2003.

[12] Lau DT, Nau DP. Oral antihyperglycemic medication nonadherence and subsequent hospitalization among individuals with type 2 diabetes. Diabetes Care 2004;27(9):2149-53.

[13] Sokol MC, McGuigan KA, Verbrugge RR, et al. Impact of medication adherence on hospitalization risk and healthcare cost. Med Care 2005;43(6):521-30.

[14] Al-Sarihin KK, Md. Bani-Khaled HRN, Haddad FH, et al. Diabetes knowledge among patients with Diabetes mellitus at King Hussein Hospital. Journal of the Royal Medical Services 2012;19(1):72-7.

[15] Omar MS, San KL. Diabetes knowledge and medication adherence among geriatric patient with type 2 diabetes mellitus. Int $\mathrm{J}$ Pharm \& Pharm Sci 2014;6(3):103-6.

[16] Safeer R, Keenan J. Health literacy: the gap between physicians and patients. Am Fam Physician 2005;72(3):463-8.

[17] Rothman RL, DeWalt DA, Malone R, et al. Influence of patient literacy on the effectiveness of a primary carebased diabetes disease management program. JAMA 2004;292(14):1711-6.

[18] American diabetes association. Standards of medical care in diabetes--2010. Diabetes Care 2010;33(Suppl 1):S11-S61. care.diabetesjournals.org.

[19] Upadhyay DK, Palaian S, Shankar PR, et al. Knowledge, attitude and practice about diabetes among diabetes patients in western Nepal. Rawal Med J 2008;33:8-11.

[20] Shrestha N, Yadav SB, Joshi AM, et al. Diabetes knowledge and associated factors among diabetes patients in Central Nepal. International Journal of Collaborative Research on Internal Medicine \& Public Health 2015;7(5):82-91.

[21] Arora S, Marzec K, Gates C, et al. Diabetes knowledge in predominantly Latino patients and family caregivers in an urban emergency department. Ethnicity and Disease 2011;21(1):1-6.
[22] Hawal NP, Shivaswamy MS, Kambar S, et al. Knowledge, attitude and behaviour regarding self-care practices among type 2 diabetes mellitus patients residing in an urban area of South India. International Multidisciplinary Research Journal 2012;2(12):31-5.

[23] Rafique G, Azam SI, White F. Diabetes knowledge, beliefs and practices among people with diabetes attending a university hospital in Karachi, Pakistan. Eastern Mediterranean Health Journal 2006;12(5):590-8.

[24] Al-Maskari F, El-Sadig M, Al-Kaabi JM, et al. Knowledge, attitude and practices of diabetes patients in the United Arab Emirates. PLoS One 2013;8(1):e52857.

[25] Al-Adsani AMS, Moussa MA, Al-Jasem LI, et al. The level and determinants of diabetes knowledge in Kuwaiti adults with type 2 diabetes. Diabetes and Metabolism 2009;35(2):121-8.

[26] Padma K, Bele SD, Bodhare TN, et al. Evaluation of knowledge and self-care practices in diabetic patients and their role in disease management. National Journal of Community Medicine 2012;3(1):3-6.

[27] Perera DP, De Silva REE, Perera WL. Knowledge of diabetes among type 2 diabetes patients attending a primary health care clinic in Sri Lanka. Eastern Mediterranean Health Journal 2013;19(7):644-8.

[28] Ng SH, Chan KH, Lian ZY, et al. Reality vs illusion: Knowledge, attitude and practice among diabetic patients. International Journal of Collaborative Research on Internal Medicine \& Public Health 2012;4(5):723-32.

[29] Saleh F, Mumu SJ, Ara F, et al. Knowledge and self-care practices regarding diabetes among newly diagnosed type 2 diabetics in Bangladesh: a cross-sectional study. BMC Public Health 2012;12:1112.

[30] Rhee MK, Cook CB, El-Kebbi I, et al. Barriers to diabetes education in urban patients: perceptions, patterns and associated factors. Diabetes Educ 2005;31(3):410-7.

[31] Hawthorne K, Tomlinson S. Pakistani Moslems with type 2 diabetes mellitus: effect of sex, literacy, known diabetic complications and place of care on diabetic knowledge, reported self-monitoring management and glycaemic control. Diabet Med 1999;16(7):591-7.

[32] Jasper US, Ogundunmade BG, Opara MC, et al. Determinants of diabetes knowledge in a cohort of Nigerian diabetics. Journal of Diabetes and Metabolic Disorders 2014;13(1):39.

[33] Feleke SA, Alemayehu CM, Adane HT. Assessment of the level and associated factors with knowledge and practice of Diabetes Mellitus among Diabetic Patients attending at FelegeHiwot Hospital, Northwest Ethiopia. Clinical Medicine Research 2013;2(6):11020.

[34] Khalid N, Khan EA, Saleem S, et al. Prevalence and associated factors of cigarette smoking among type 2 diabetes patients in Pakistan. International Journal of Collaborative Research on Internal Medicine \& Public Health 2014;6(4):73-88. 
[35] Jagtap MW, Rohankar PH, Kale SA. Exercise reduces HBA1C and mostly brings good control in type 2 diabetes mellitus. International Journal of Science and Research 2015;4(10):902-4.

[36] Nazir SUR, Hassali MA, Saleem F, et al._Disease related knowledge, medication adherence and glycaemic control among patients with type 2 diabetes mellitus in Pakistan. Primary Care Diabetes 2016;10(2):13641.
[37] Mahmood MI, Daud F, Ismail A. Glycaemic control and associated factors among patients with diabetes at public health clinics in Johor, Malaysia. Public Health 2016;135:56-65.

[38] Abiodun OA, Jagun OA, Olu-Abiodun 00, et al. Correlation between Body mass index, Waist Hip ratio, blood sugar levels and blood pressure in apparently healthy adult Nigerians. IOSR Journal of Dental and Medical Sciences 2014;13(11):56-61.

www.iosrjournals.org. 